IJBPAS, November, Special Issue, 2021, 10(11): 1059-1068

ISSN: 2277-4998

International Journal of Biology, Pharmacy

and Allied Seiences (IJBPAS)

'A Bridge Betusen Caboratory and QReador'

WwW.iibpas.com

\title{
PREDICTION OF CRYSTALLINE SUBSTANCE FORMS IN THE EARLIER STAGE THROUGH DRUG DEVELOPMENT TECHNIQUE
}

\section{VIJAYA SRI KOMPALLI ${ }^{1 *}$, DHAMOTHARAN A ${ }^{2}$, TASNEEM K.H.KHAN ${ }^{3}$ AND MAHIMA. $\mathbf{R}^{4}$}

1: Computer Science and Engineering, Koneru Lakshmaiah Education Foundation, Vaddeswaram, Andhra Pradesh, India

2: Assistant Professor in Chemistry, Builders Engineering College, Kangayam

3: Assistant Professor in Chemistry, Anjuman College of Engineering and Technology, Sadar, Nagpur, Maharashtra, India

4: Assistant Professor in Electronics and Communication Engineering, K.Ramakrishnan College of Engineering, Samayapuram, Trichy, Tamil Nadu, India

*Corresponding Author: Vijaya Sri Kompalli; E Mail: kompallivsri@gmail.com

Received 23 ${ }^{\text {rd }}$ July 2021; Revised $27^{\text {th }}$ Aug. 2021; Accepted $30^{\text {th }}$ Sept. 2021; Available online $1^{\text {st }}$ Nov. 2021 https://doi.org/10.31032/IJBPAS/2021/10.11.1091

\begin{abstract}
Under environmental conditions, this thermodynamically most steady polymorph was usually always the most acceptable crystalline shape for pharmaceutical development. As a result, discovering or characterizing this polymorph at the quickest feasible development stage was advantageous. Early in the pharmaceutical research process, a screen was created or published to locate the stable polymorphic of a pharmacological compound. A small quantity of chemical was suspended for two weeks in a variety of solvents in deal to crystallize the most viable polymorphic. Absorption of a component in each of the substances used in the robust polymorphic screen was established using a simple spectrometric approach. Ritonavir and the potential of initial stages (Compound A from Pfizer) were used an instance compounds to
\end{abstract}


appreciate the potential of a web for discovering to most feasible polymorphism earlier as in vaccine development process.

\section{Keywords: Crystalline Substance; Drug development technique; Molecules}

\section{INTRODUCTION}

Polymorphism was common in pharmaceutical substances. Because each polymorph can have distinct pharmaceutically relevant qualities, this phenomenon has piqued of industry's interest. It would be hugely critical to determine the polymorphic that was thermodynamically a most robust under environmental factors. The risks of marketing to medicine without being aware of and identifying the thermodynamically most stable configuration have been extensively observed [1]. Because it has the smallest susceptibility to convert throughout scale-up, manufacturing, composition, and retention [2], the thermodynamically most stable shape would be almost usually regarded a most ideal hexagonal structure to produce. A metastable crystalline structure was usually created on development unless it represents a significant improvement in drug dissolution velocity, that could improve ingestion or bioavailability over drug robust polymorphic. Given this predilection for the most robust polymorphic, finding or characterizing this polymorphic at fast feasible development process would be advantageous [3].

Re-crystallization from a large variety of substances by temperature, anti-solvent addition, and evaporated was presently the industrial norm for initial phase morphological screening. Although obtaining the stable polymorphic is an important objective of these re-crystallizations, these processes intrinsically prefer meta-stable forms, according to Ostwald's Steps Rule. However, initially as in medicine development phase, chemical availability or time restrictions prohibit thorough recrystallization methods [4]. As a result, smaller drug batches, a limited amount of recrystallizations are often conducted early on. A comparative thermodynamic viability of forms generated by crystallization screen was frequently determined using competition slurries [5].

Re-crystallization screen cannot assure the most stability polymorphic would be created for use in competitive sludge since early re-crystallizations enhance metastable molecules. As a result, robust polymorphic should aggregate during competitive droplets 
in order to attain the intended result [6]. Because of these constraints, more robust polymorphic could be overlooked as in recrystallization display or was discovered late in the design process or after approval. A error could result in significant delays in innovation development and planning authorization, reducing a company's income. A technique for adequately acquiring and maintaining only stable crystalline polymorphic at early possible point of development was necessary to avoid the problems associated with the initial production of a thermodynamic crystalline state [7].

A most stable polymorph could clearly be generated through solvent-mediated polymorphic conversion. This strategy is appealing during early stages because trials could be devised to meet time and supply constraints [8]. This sludge or ageing experiments would be premised on the reality that a concentrated solution of any thermodynamic polymorphic was supersaturated when compared to its most robust polymorphic. The more stable polymorph would crystallize if given enough time to achieve thermodynamic equilibrium and reduce supersaturated. [9] Investigated the parameters that determine the pace of preservative polymorphism conversions using sulfamerazine as a model polymorphism medication, indicating that vehicles that give the optimal balance of chemical liquidity and preservative correlations provide the fastest exchange rates. This pioneering work on detergent sulfamerazine translation spurred the development of the stability polymorphic screen [10].

\section{METHODS}

Ritonavir "form" I was recrystallized from an extraction solvent of 2:1 heptanes:ethyl acetate. Slurring "form" I in methanol of four days to around 21 degrees Celsius yielded ribavirin "form" II. Reference Figure 1 shows the PXRD characteristics of ribavirin forms I and II. A robust technique for detecting seeds was used to check for small concentrations of form II as in form I elements [11]. The approach, which has been reported to detect form II in the range of $1 \mathrm{pm}$, as in forms my base material. Compound A was taken via Pfizer's ingredient inventory. Form I was identified as the original form, and this substance was used in constant polymorphism screen as-is. 


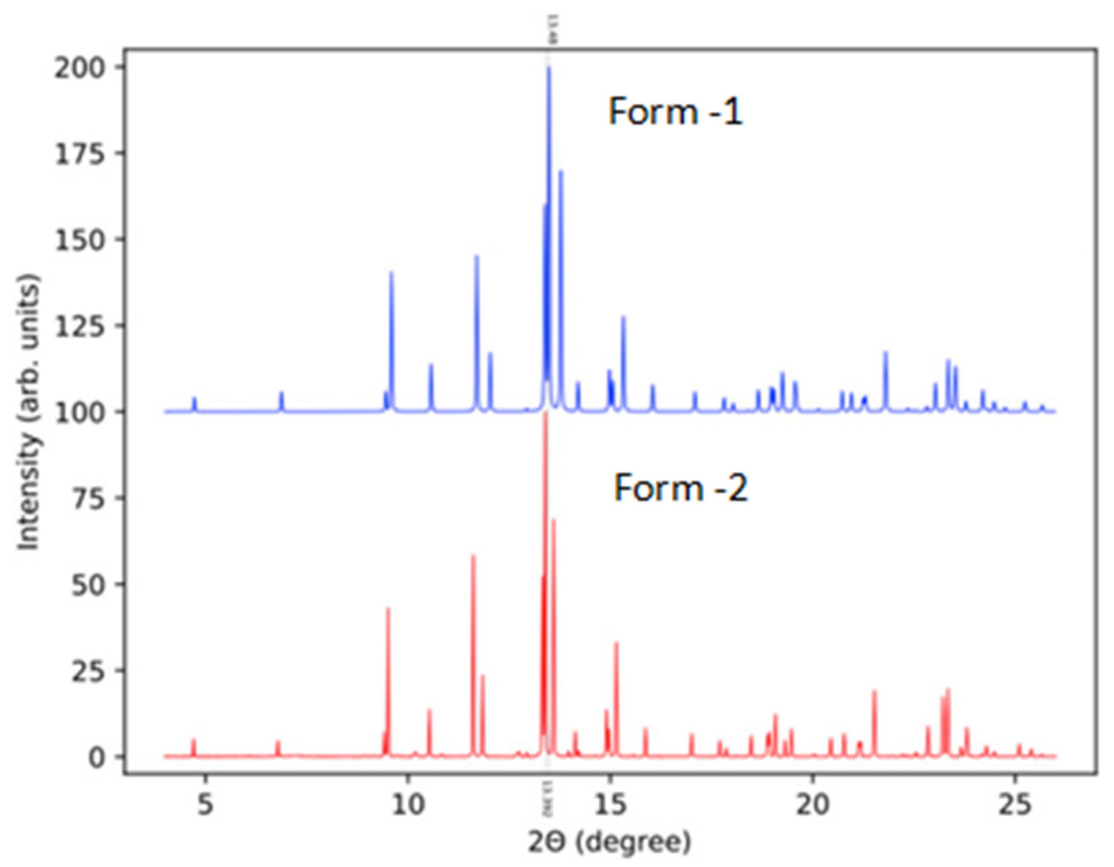

Figure 1: Ritonavir powder patterns

A test chemical was dissolved in a number of different liquids with varying dielectric permittivity. An amount of surplus solid and the solvent volume as in dispersion was different based to saturation of mixture in certain solvent and the compound availability. Magnetic stir bars coated with polytetrafluoroethylene were used to stir the suspensions at $500 \mathrm{rpm}$ in a stir board. Concentrations were kept at $25^{\circ} \mathrm{C}$ using flowing distilled water. At two-day and twoweek intervals, a part of suspension was taken and processed using $0.45 \mathrm{~mm}$ PTFE filters. PXRD was used to establish the material state's polymorphic identification. Compound's mobility was examined in duplicate over a two-week period using a weighing balance, with $50 \mathrm{ml}$ of methanol to each mixture autoclaved into alumina crucible of specified weight. A solvent was then dissolved in a pressure electric stove at 120 degrees Celsius in each plate. Mettler MT5 microbalance was then used to determine the mass of leftover solid. The sensitivity of a component in each solvent was calculated by dividing the mass of the residual solid by comparable amount of acceptable solvent.

For permanent polymorphic detection of ritonavir, PXRD patterns were captured using an XRD, Japan made using $\mathrm{Cu}$ irradiation running to $40 \mathrm{kV}$ or $40 \mathrm{MA}$. Because of its greater resolution and larger 2theta frequency, the Rigaku equipment was employed for permanent polymorphism detection of ritonavirOn a separate X-ray 
diffractometer, PXRD investigations for permanent polymorphism detection of Pfizer product $\mathrm{A}$ were carried out using $\mathrm{Cu} \mathrm{Ka}$ radiation with $40 \mathrm{kV}$ and $40 \mathrm{~mA}$. Scans were done at 2-theta with a 60 -second scan period and a $1 \mathrm{~mm}$ specimen amplitude. Faster runs were possible thanks to the Bruker system, which would be commonly required for accurate polymorphic detection of a large number of antibiotics under investigation.

\section{RESULTS AND DISCUSSION}

A solvent-mediated polymorphic transformation approach is shown in Figure 2. The first phase of this process is metastable polymorphic degradation, accompanied by polymerization and subsequently crystal production of thermodynamically stable polymorphism. Because of most robust polymorphic would be the least solvent, a concentrated solution of a less robust polymorphic was completely saturated in compared to more permanent polymorphic. Supersaturated solutions were thermodynamically stable; slurries of less robust morphologies would convert into slurries of more robust polymorphic given enough duration. A compromise between structure's mobility in that solvent as well as the intensity of dispersed interactions in that solvent controlled the rate of preservation adoptions. As a consequence, assessing dispersibility as part of stable polymorphic screen is essential for selecting solvents with limited stability. Because solubilities were assessed simultaneously as in web, it was possible to test a huge amount of solvents with a big range in polarity of boost the possibilities to finding mixtures with ideal or at least strong enough dispensability to stimulate a rapid transformation.

HIV-protease antagonist ritonavir and instance to late identification in thermodynamically robust polymorphism might affect drug continual improvement. Polymorphic of ritonavir is at the time of its introduction or beginning production. To enhance the drug's bioavailability, this polymorphism is created in the form of a semisolid compartment.

A thermodynamically more stable polymorph suddenly emerged from the formulation just two years after the product was manufactured. As a result of this occurrence, the formulation failed dissolution testing, and the product was pulled from the market.

Results of the ritonavir stable polymorph screen were summarized in Table 1. The metastable form I served as the screen's beginning point. There were no visible seeds to form II and form I starting component, which may have aided the shift of the stable phase. Solvents to instability 
with $250 \mathrm{mg} / \mathrm{ml}$ was not taken into study as it possess dense dispersion or restricted of component.

A stable polymorph screen found Form II of ritonavir. In 3 days, conversion takes place from form 1 to form 2 was seen in 8 of the 13 substances. Within two weeks, ten of thirteen solvents had completed conversion. Fig 3 illustrates the change form from 1 to 2 through PXRD of form I component after 3 days from 2-propanol. Mobility was $5.4 \mathrm{mg} / \mathrm{ml}$, the changeover occurred faster in overall. This finding backs up the idea of a solubility threshold that was previously suggested. In investigations conducted by GU and colleagues, solubility larger than $8 \mathrm{~mm}$ was required to assure polymorph transition of sulfamerazine form I and form II. Figure 2 reveals that solubility would be the most important element in ritonavir conversions from form I and form II, which explained by extremely high form I/form II solubility ratio. A greater level of super saturation, which would be equal in diverse solvents at temperature, reflects a substantial variation in fusion power between morphologies. The primary driver required to break the free electricity limit and permit the position to form or develop would be significant difference in renewable power between forms I and II.
Within two days, condensation of form II occurs in preparation in water or hexanes. After two weeks, although, continuous or intermittent transition to form II was found, indicating a prolonged reaction rate for condensation in low-solubility liquids. As a result, in solvent to lesser mixtures, Form II precipitation is less likely, making the thermodynamic Form I kinetic model robust in solvents. The lack of a shift from form 2 to 2 in solubility solvent highlighting importance on exact dispersion in order to preserve maximum polymorphism statement of stability. A absorption values of form 2 in ethanol as well as methanol obtained using specific gravity method match preliminary studies substantially (with 10\%).

Pfizer compound A was a solid form screening candidate obtained early in the development process. The results of Pfizer compound A's stable polymorph screen were summarised in Table 2. Form I was the first form accepted, and it was submitted to robust polymorph screen. After two days, six of 18 solvents had converted to their most permanent dehydrated polymorphism (form II), eight of 18 had transitioned in two days. In the 1, 4-dioxane mixture, transformation to a more robust solvate is observed. A shift of permanent polymorphic proceeded more 
quickly in solvents with solubility, similar to ritonavir.

In addition to gaining a meaningful awareness of permanent polymer, data of web could use to permanent form scale-up efforts, as was case with Pfizer medication. Using the acquired knowledge from mobility polymorph screen, the thermodynamically form II of Pfizer combination were made in huge scale. Since this conversion dynamics were fast, the bioavailability were poor, ethyl acetate was used on a massive scale for conversion, resulting in a larger output. Dynamic of solvent-mediated transition to initial stage chemical substance in ethanol at $25 \mathrm{C}$ was studied using in-situ Spectroscopic methods. Transformation to form II took only 36 hours due to high matrix results.

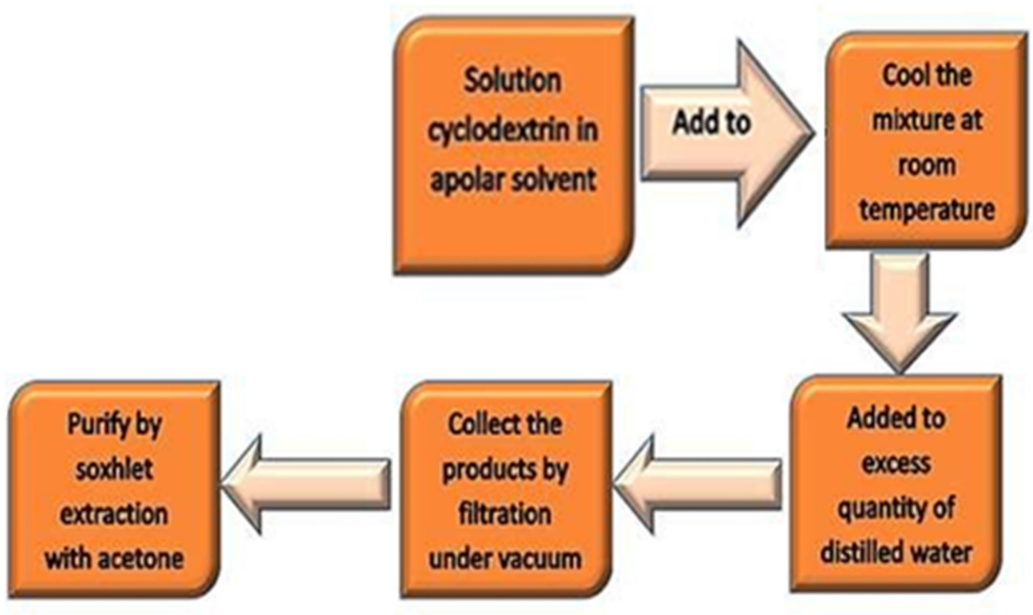

Figure 2: Shows the steps in the solvent preparation method

Table 1: Ritonavir stability outcomes

\begin{tabular}{|c|c|c|c|}
\hline & Solid appearance 3 days & Solid appearance 4 weeks & Solution in mg/ml \\
\hline Entity & 2 & 2 & 5.23 \\
\hline Nitro methane & 2 & 2 & 5.25 \\
\hline Acthyl acetate & 2 & 2 & 6.98 \\
\hline Propanol & 2 & 2 & 14.5 \\
\hline Butanone & 2 & 2 & 18.6 \\
\hline
\end{tabular}

Fig 2 Observations of polymorph at early stage

\begin{tabular}{|c|c|c|c|}
\hline & Solid appearance 3 days & Solid appearance 4 weeks & Solution in mg/ml \\
\hline Entity & 1 & 1 & 2.74 \\
\hline Methanol & 2 & 2 & 3.44 \\
\hline Chloroforms & 2 & 2 & 6.05 \\
\hline Acetone & 2 & 2 & 8.55 \\
\hline Hexane & 1 & 1 & 0.13 \\
\hline
\end{tabular}




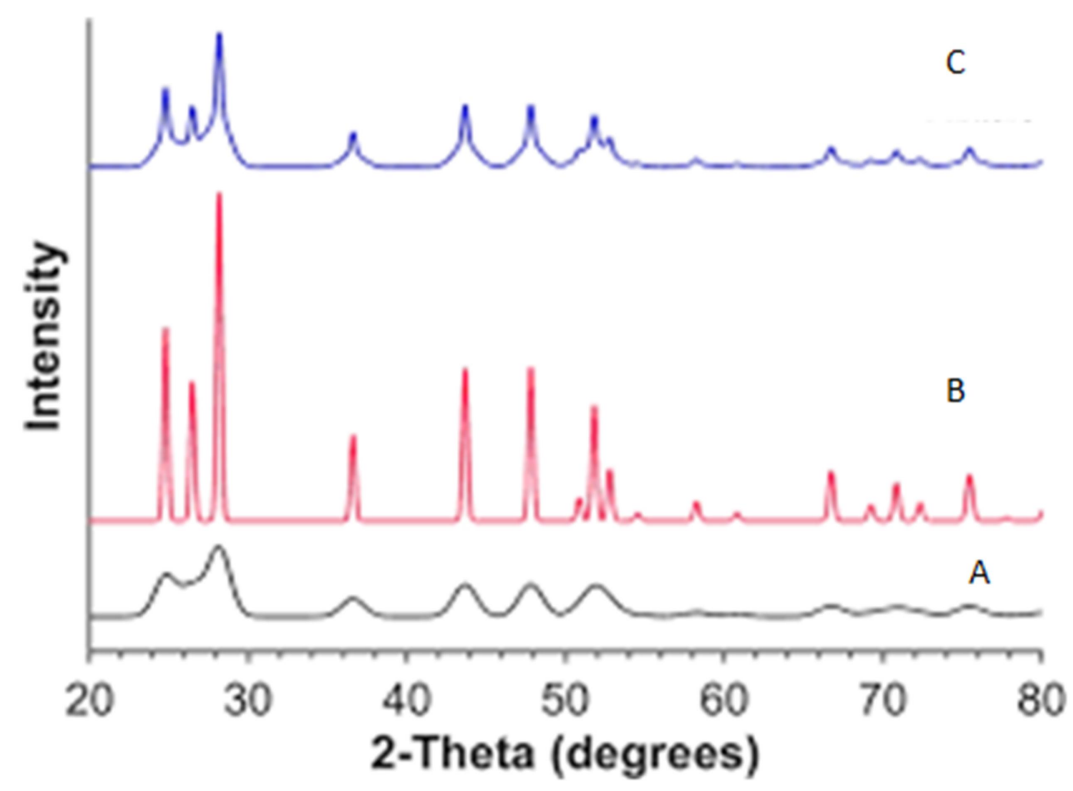

Figure 3: Ritonavir PXRD: (A) starting substance; (B) form 2 in 3 days of propanol

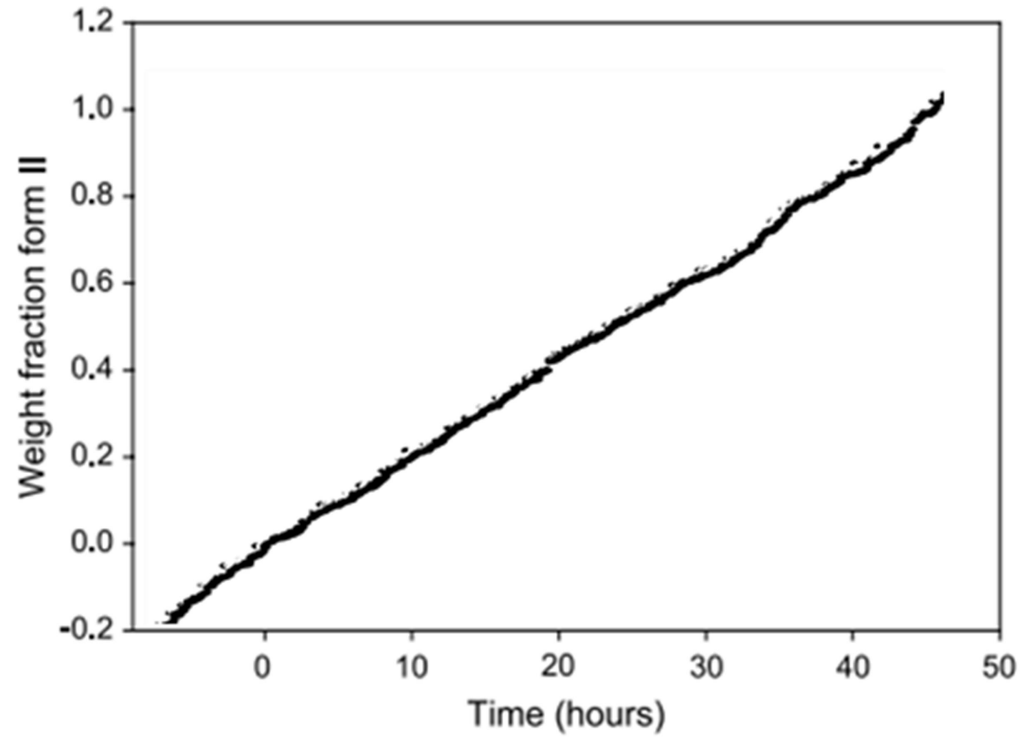

Figure 4: Kinetics of an early development candidate's solvent-mediated conversion

\section{CONCLUSIONS}

Using a little quantity of compound (100-250 mg) and a tiny quantity of compound (100-250 mg), we provided a simple screen to receiving more permanent polymorphism of initial detection molecules. We used ritonavir and an early stage candidate of established efficacy of method the determining most permanent polymorphic (Pfizer compound A). According to constrained information $(n=43)$, roughly $26 \%$ of initial finding substances (acquired as crystal structures) converted to more permanent morphologies during 
permanent polymorphic screen. More stable polymorphs have yet to be discovered in any of the 43 candidates who have progressed to improvement stage. Implementing solventmediated polymorphism transformation to identify the thermodynamically most robust polymorphism early in the process of discovery has substantial downsides. The presence of defects in some solvents, even in trace quantities, could impede the condensation of most stable form. Inadequate solubility or polymerization inhibition mediated by solvent-solute interaction could make conversion to stable polymorph difficult. The data, when combined with previous studies, illustrate that for conversion, penetration of at least $8 \mathrm{~mm}$ is normally required.

\section{REFERENCES}

[1] Sun G, Jin Y, Li S, Yang Z, Shi B, Chang C, Abramov YA. Virtual coformer screening by crystal structure predictions: Crucial role of crystallinity in pharmaceutical cocrystallization. The Journal of Physical Chemistry Letters. 2020 Sep 24;11(20):8832-8.

[2] Yang M, Dybeck E, Sun G, Peng C, Samas B, Burger VM, Zeng Q, Jin Y, Bellucci MA, Liu Y, Zhang P. Prediction of the relative free energies of drug polymorphs above zero kelvin. Crystal Growth \& Design. 2020 Jul 1;20(8):5211-24.

[3] Greenwell C, McKinley JL, Zhang P, Zeng Q, Sun G, Li B, Wen S, Beran GJ. Overcoming the difficulties of predicting conformational polymorph energetics in molecular crystals via correlated wavefunction methods. Chemical science. 2020;11(8):220014.

[4] Devogelaer JJ, Meekes H, Tinnemans P, Vlieg E, De Gelder R. Co-crystal Prediction by Artificial Neural Networks. Angewandte Chemie. 2020 Nov 23;132(48):21895-902.

[5] Pandi P, Bulusu R, Kommineni N, Khan W, Singh M. Amorphous solid dispersions: An update for preparation, characterization, mechanism on bioavailability, stability, regulatory considerations and marketed products. International journal of pharmaceutics. 2020 Aug 30;586:119560.

[6] Kalaria DR, Parker K, Reynolds GK, Laru J. An industrial approach towards solid dosage development for first-in-human studies: Application of predictive science and lean principles. Drug discovery today. 2020 Mar 1;25(3):505-18. 
[7] Cote A, Erdemir D, Girard KP, Green DA, Lovette MA, Sirota E, Nere NK. Perspectives on the Current State, Challenges, and Opportunities in Pharmaceutical Crystallization Process Development. Crystal Growth \& Design. 2020 Nov 5;20(12):7568-81.

[8] Cote A, Erdemir D, Girard KP, Green DA, Lovette MA, Sirota E, Nere NK. Perspectives on the Current State, Challenges, and Opportunities in Pharmaceutical Crystallization Process Development. Crystal Growth \& Design. 2020 Nov 5;20(12):7568-81.

[9] Cote A, Erdemir D, Girard KP, Green DA, Lovette MA, Sirota E, Nere NK. Perspectives on the Current State, Challenges, and Opportunities in Pharmaceutical Crystallization Process Development. Crystal Growth \& Design. 2020 Nov 5;20(12):7568-81.

[10] Woodley SM, Day GM, Catlow R. Structure prediction of crystals, surfaces and nanoparticles. Philosophical Transactions of the Royal Society A. 2020 Dec 11;378(2186):20190600.
[11] Pepin XJ, Parrott N, Dressman J, Delvadia P, Mitra A, Zhang X, Babiskin A, Kolhatkar V, SuarezSharp S. Current state and future expectations of translational modeling strategies to support drug product development, manufacturing changes and controls: a workshop summary report. Journal of pharmaceutical sciences. 2021 Feb 1;110(2):555-66. 